\title{
Medical-legal concerns over prescribing opioids on the rise
}

- Cite as: CMAJ 2017 October 10;189:E1270-1. doi: 10.1503/cmaj.109-5500

Posted on cmajnews.com on Sept. 19, 2017.

arol Ward confronted a Manitoba doctor in 2014 with a photo of her daughter, Lisa Erickson, injecting drugs. She pleaded with the doctor to stop prescribing morphine to her daughter, who she said had a drug addiction and didn't need opioids. Last spring, Erickson died of an overdose at age 32.

Ward talked to a lawyer about filing a malpractice lawsuit but was discouraged. "He told me it would go on for years and, even if I won, I'd be broker than I was when I started." So, instead, she's filing a complaint with the College of Physicians and Surgeons of Manitoba, but says, "I don't have a lot of faith in the college process."

New data from the Canadian Medical Protective Association (CMPA) and provincial regulatory agencies suggest physicians rarely face serious discipline in opioid-related cases. An increase in investigations and monitoring, however, has many doctors worried.

The CMPA handled 151 medical-legal cases involving allegations of patient harm related to opioid prescribing between 2010 and 2015. (The CMPA wouldn't provide details on cases, including whether any involved financial settlements.) The number of phone calls from doctors with legal concerns related to opioid prescribing has risen steadily over the past five years.

Dr. Todd Watkins, managing director of physician services at CMPA, said the increase is "in part due to the much greater attention being paid to the social crisis that is opioid addiction, and a change in the clinical philosophy related to the use of opioids and pain control."

The CMPA's new subsidiary, Saegis, recently partnered with the University of

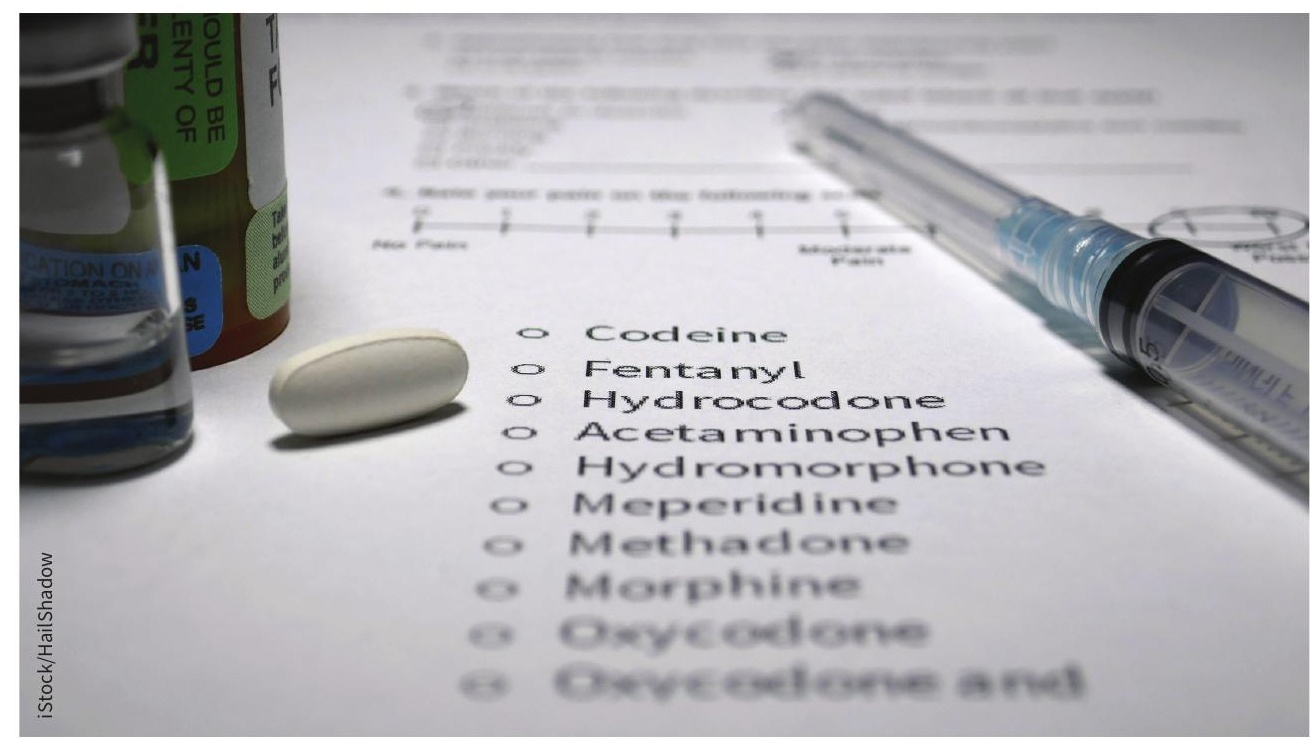

Physicians rarely face serious discipline in cases related to prescribing opioids.

Toronto to expand the university's safer opioid prescribing program to physicians across the country. Dr. Hartley Stern, chair of the Saegis board, said doctors "are encouraged to take opioid education sessions to reduce their medical-legal risk and improve patient safety."

The College of Physicians and Surgeons of Ontario released information earlier this month about 84 doctors flagged by the ministry of health for prescribing opioids in excessive amounts. Only one doctor so far will face a disciplinary hearing. Three have restrictions placed on their licences barring them from prescribing narcotics and some other substances. Others are being required to take additional training or undergo supervision and monitoring of their opioid prescribing practices. Another 28 are still under investigation.

Dr. Andrew Kolodny, codirector of opioid policy research at the Heller School for
Social Policy and Management in Massachusetts, thinks more doctors should have been disciplined. "The college is ... supposed to protect the public from doctors practising in a reckless or dangerous way. The fact that there were over 80 doctors prescribing these amounts in the first place and, without a doubt, killing people was a failure of the regulatory system," he said.

The college in Ontario, like those across the country, tends to take a remedial rather than punitive approach to opioid-overprescribing cases, which means working with physicians to improve their prescribing habits. Dr. Rocco Gerace, registrar of the Ontario college, said that remediation takes into account the larger population of patients who depend on a doctor. "The last thing that would be appropriate is to take 80 doctors out of practice ... simply to meet the expectations of some of our critics," he said. 
In Alberta, only one doctor has been disciplined for overprescribing opioids. The physician, who prescribed the equivalent of $240 \mathrm{mg} /$ day of morphine in combination with benzodiazepines to a young mother who later died of overdose, avoided a three-month license suspension by fulfilling certain conditions, including undergoing updated training. Other doctors in the province have had restrictions placed on the drugs they can prescribe.

Kelly Eby, director of communications and government relations at the College of Physicians and Surgeons of Alberta, suggested that more punitive approaches might discourage doctors from prescribing opioids when necessary. If patients are "cut off, or their subscription is reduced dramatically, they're going to go elsewhere, and that means to the street."

In British Columbia, no doctors have had their licences suspended or revoked in recent years because of harmful prescribing of opioids. The College of Physicians and Surgeons of British Columbia receives about 60 complaints per year about opioid prescribing, according to
Susan Prins, the college's director of communications and public affairs. Prins added that taking a more disciplinary approach to handling these cases might discourage doctors from "accepting and retaining patients with chronic, complex pain."

According to Kolodny, however, this concern is misguided. "If you look at the level of opioid prescribing in Canada and in the US, it's far in excess of what could possibly be needed," he said.

Wendy Glauser, Toronto, Ont. 